\title{
Research Paper: Ischemic Postconditioning Attenuates Bilateral Renal Ischemia-induced Cognitive Impairments
}

\author{
Mahshid Tahamtan'1 (D, Abbas Nazari² (D), Iraj Aghaei ${ }^{3}$, Mohammad Shabani $^{4^{*}}$ (D) \\ 1. Department of Neuroscience, School of Advanced Medical Sciences and Technologies, Shiraz University of Medical Sciences, Shiraz, Iran \\ 2. Department of Biology, Shiraz Branch, Islamic Azad University, Shiraz, Iran. \\ 3. Neuroscience Research Center, Poursina Hospital, Guilan University of Medical Sciences, Rasht, Iran. \\ 4. Neuroscience Research Center, Neuropharmacology Institute, Kerman University of Medical Sciences, Kerman, Iran.
}

\begin{tabular}{|c|c|}
\hline $\begin{array}{l}\text { Use your device to scan } \\
\text { and read the article online }\end{array}$ & Cittation Tahamtan, M., Nazari, A., Aghaei, I., \& Shabani, M. (2021). Ischemic Postconditioning Attenuates Bilateral Renal \\
\hline 口inist: & $\begin{array}{l}\text { Ischemia-induced Cognitive Impairments. Basic and Clinical Neuroscience, 12(6), 789-804. http://dx.doi.org/\%2010.32598/ } \\
\text { bcn.2021.1941.1 }\end{array}$ \\
\hline 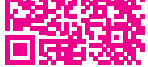 & doij http://dx.doi.org/10.32598/bcn.2021.1941.1 \\
\hline
\end{tabular}

\section{(1) (3)}

Article info:

Received: 20 Jul 2019

First Revision: 13 Apr 2020

Accepted: 14 Jun 2020

Available Online: 01 Nov 2021

Keywords:

Cognitive impairments, Acute kidney injury, Postconditioning, Brain-derived Neurotrophic Factor, Bilateral renal ischemia

\begin{abstract}
AB S T RACT
Introduction: Acute Kidney Injury (AKI) is a frequent complication of kidney failure with high mortality, leading to brain dysfunction. This study aimed to investigate the possible protective effect of Ischemic Postconditioning (IPo) against brain dysfunction induced by Bilateral Renal Ischemia (BRI).

Methods: Male Wistar rats underwent BRI, sham, or IPo surgery 24h and $1 \mathrm{w}$ after reperfusion. The rats' explorative behaviors and motor function were evaluated by an open field, rotarod, and wire grip tests. The cognitive function was assessed by passive avoidance learning and Morris water maze tests. Western blotting was performed to evaluate hippocampal BrainDerived Neurotrophic Factor (BDNF) expression.

Results: The impairment of balance function induced by BRI was not reversed; however, passive avoidance learning impairment was reversed by postconditioning $24 \mathrm{~h}$ after reperfusion. IPo increased muscle strength compared to the BRI group; however, explorative behaviors and balance function had no difference $1 \mathrm{w}$ after reperfusion. BRI significantly decreased the BDNF protein expression in the hippocampus, and postconditioning increased $24 \mathrm{~h}$ after reperfusion.

Conclusion: The obtained results demonstrated the deleterious effect of BRI on cognitive and balance function $24 \mathrm{~h}$ after reperfusion. IPo indicated a curative effect against cognitive dysfunction probably by enhancing BDNF protein expression in the hippocampus.
\end{abstract}

\section{* Corresponding Author:}




\section{Highlights}

- IPo improved passive avoidance learning impairment induced by BRI.

- IPo increased muscle strength compared to the BRI group.

- BRI significantly decreased the BDNF protein expression in the hippocampus.

- IPo increased BDNF protein expression 24h after reperfusion.

\section{Plain Language Summary}

Acute kidney injury may be associated with numerous complications in different regions of brain, as it may alter the permeability of the blood-brain barrier, accumulate the toxins, decreased blood flow to the brain, increased risk of encephalopathy, higher mental dysfunctions like delirium, stroke, memory and thinking problems (dementia) in people with kidney failure. It has been demonstrated that the most common causes of mortality in acute kidney injury is brain dysfunction. Therefore, discovering new treatments can decrease the brain injuries and help the patients with kidney dysfunction to have a higher quality of life. Ischemic postconditioning, which refers to a series of brief ischemia and reperfusion cycles applied immediately at the site of the ischemic organ after reperfusion, results in reduced injuries induced by ischemia. The purpose of the current study was designed to investigate whether ischemic postconditioning exerts neuroprotective effects against brain dysfunctions induced by renal ischemia in rats. Results of this study demonstrated that acute kidney injury triggers distant organ dysfunction and leads to cognitive and balance dysfunction 24h after induction of renal ischemia and ischemic postconditioning protects the brain as a remote organ against cognitive dysfunction from the injury induced by renal ischemia.

\section{Introduction}

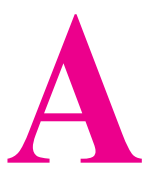

cute Kidney Injury (AKI) is a frequent complication, i.e., associated with increased hospital stay and mortality (Hussein, Barakat, Awadalla, \& Shokeir, 2012; Khatri, Himmelfarb, Adams, Becker, K., Longstreth, \& Tirschwell, 2014). Renal Ischemia-Reperfusion Injury (Renal IRI) is one of the most important causes of AKI and can lead to remote organ dysfunction like lung, brain, and heart (Hassoun et al., 2007).

Patients with AKI suffer from high levels of mental and cognitive dysfunctions. Synthesizing the results of the previous studies, AKI caused cellular and soluble inflammation, edema, alterations in water transport, and increased microvascular protein leakage in the brain (Arieff \& Massry, 1974; Arieff, Massry, Barrientos, \& Kleeman, 1973; Liu et al., 2008). Due to the inflammatory response, the disruption of the $\mathrm{BBB}$, endothelial injury, and stimulation of the coagulation cascades within the brain have been observed, leading to alterations in neuronal cell protein transcription and cellular activation. Furthermore, an increased number of pyknotic neuronal cells and microgliosis following $60 \mathrm{~min}$ of renal isch- emia in the CA1 region of the brain hippocampus, compared to the sham group, has been indicated (Kinsey, Li, \& Okusa, 2008; Liu et al., 2008). Another research also reported increased GFAP and microglia cells as distant organ consequences of AKI (Kinsey et al., 2008; Liu et al., 2008; Ratliff, Rabadi, Vasko, Yasuda, \& Goligorsky, 2013; TSAO, Hsu, Wu, Liu, \& Lei, 2001). These changes were implicated in causing altered brain function (Nongnuch, Panorchan, \& Davenport, 2014).

Bilateral renal ischemia has been introduced as the leading cause of AKI in patients. Since ischemia/reperfusion can cause irreversible damages to tissue and mechanisms contributing to the pathogenesis of ischemia-reperfusion injury are complex, new strategies like ischemic conditioning have been explained to increase tolerance and protect against ischemia-reperfusion injury (Seifi, Kadkhodaee, Najafi, \& Mahmoudi, 2014). In ischemic conditioning, brief intermittent and reversible episodes of ischemia with reperfusion can induce protective effects against ischemia/ reperfusion injury. These processes were defined based on this phenomenon: ischemic preconditioning and Ischemic Postconditioning (IPo).

Ischemic preconditioning is a powerful intervention against IRI; however, it is clinically feasible because, in 
most cases, ischemia is not predictable (Zhao, Sapolsky, \& Steinberg, 2006). Several studies introduced IPo as a new neuroprotective strategy to deal with IRI (Penna, Tullio, Moro, Folino, Merlino, \& Pagliaro, 2010; Wever, Menting, Masereeuw, van der Vliet, Rongen, \& Warlé, 2012; Zhao et al., 2003). It is the phenomenon that brief, repetitive cycles of ischemia during the onset of reperfusion can be protective in different systems (Penna et al., 2010; Wang et al., 2008; Wever et al., 2012) and can attenuate the potential additional injury which may be induced by reperfusion. Thus, IPo has become a clinical application to significantly decrease IRI (Deftereos et al., 2013; Liu et al., 2009; Lønborg et al., 2010). However, the detailed mechanism of postconditioning remains unknown. Discovering involved mechanisms in postconditioning may shed light on finding effective treatment against injuries.

Neurotrophins are neuroprotective factors that exert their effects through intracellular signaling pathways. Brain-Derived Neurotrophic Factor (BDNF) is a member of the neurotrophin family, which plays a prominent role in neuronal survival, plasticity, learning, and memory. Moreover, the vital role of BDNF in neurological function following brain injury has been indicated. Several studies discriminated the protective role of BDNF following neonatal hypoxic_ischemic brain injury, transient, and focal cerebral ischemia, and stroke (Melo et al., 2013; Singh \& Su, 2013; Vetrovoŭ, Rybnikova, \& Samoĭlov, 2013).

There is a growing body of evidence that hypoxic and ischemic postconditioning up-regulate the expression of BDNF, particularly in hippocampal CA1 neurons in rats (Vetrovoi, Rybnikova, Glushchenko, \& Samoilov, 2015; Vetrovoĭ et al., 2013; Zen'ko, Rybnikova, \& Glushchenko, 2013; Zhang et al., 2015).

Several studies outlined the protective effects of postconditioning in the heart (Kin et al., 2005; Kin et al., 2004; Tsang, Hausenloy, Mocanu, \& Yellon, 2004), brain (Ren et al., 2008; Zhao, 2009; Zhao, Sapolsky, \& Steinberg, 2006), liver (Sun, Liu, \& Sun, 2004), and kidney (Liu et al., 2007); however, there is no study to examine the effects of renal IPo on brain damage induced by renal IRI. The study aimed to investigate: 1) whether IPo will be able to prevent memory and motor deficits, 2) whether IPo causes protective effects by alteration in BDNF level.

\section{Methods}

\section{Animal preparation and experimental design}

Adult male Wistar rats (8-10 weeks old, 180-220 g) were used in this experiment and fed with standard rat chow and water ad libitum. The animals were housed under a controlled temperature $\left(21-23^{\circ} \mathrm{C}\right)$ and $12: 12 \mathrm{~h}$ light/dark cycle. All animals’ procedures were observed to minimize pain and were approved by the Kerman Medical University Ethics Committee (EC/KNRC/92$6)$. There were 6 different groups of rats in the current study. The rats subjected to Bilateral Renal Ischemia/reperfusion (BRI) were divided into 2 groups of $n=10$, in which the right and left renal arteries and veins were occluded for $1 \mathrm{~h}$ that followed by the reperfusion periods of 24 hours (BRI-24h group) and 1 week (BRI-1w group). The sham-operated rats were divided into 2 groups of $\mathrm{n}=10$ that animals underwent only anesthesia without occlusion with periods equivalent to reperfusion of 24 hours (sham-24h group) or 1 week (sham-1w group).

IPo animals were also divided into 2 groups $(n=10 /$ group) subjected to $60 \mathrm{~min}$ ischemia, then 3 cycles of $10 \mathrm{~s}$ of reperfusion followed by $10 \mathrm{~s}$ ischemia in the reperfusion periods of 24 hours (IPo-24h group) and 1 week (IPo-1w group). This model of postconditioning was based on the methods described before (Figure 1) (Guo et al., 2014).

Inducing bilateral renal ischemia/reperfusion and ischemic postconditioning

The study rats were anesthetized with ether, and a midline laparotomy was performed. The renal arteries and veins were occluded with non-traumatic clamps. The occlusion was verified visually by a color change of the kidney to a paler shade. The clamps were isolated at the end of the ischemic period, and blood was reperfused. The kidneys were treated identically in sham-operated control rats, except for clamping. In ischemic postconditioning-operated rats after $60 \mathrm{~min}$ of occlusion to induce ischemia, 3 cycles of ischemia $(10 \mathrm{sec})$ followed by reperfusion $(10 \mathrm{sec})$ exerted.

The abdominal incision was sutured at two layers by 2-0 silk. All surgical procedure was done under sterile condition, and the rat was allowed to recover from the anesthesia before returning to an individual cage. The Kerman University approved the surgical protocol of Medical Sciences. Behavioral assays were performed $24 \mathrm{~h}$ or 1 week after surgery with a $2 \mathrm{~h}$ interval among each assay in the following order: open field test, rotarod, 
Sham

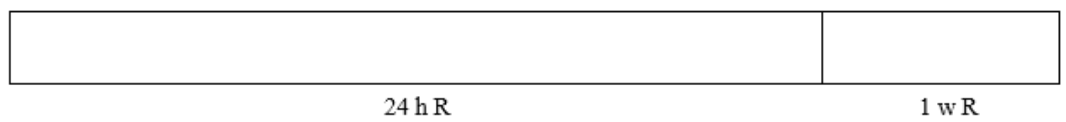

BRI

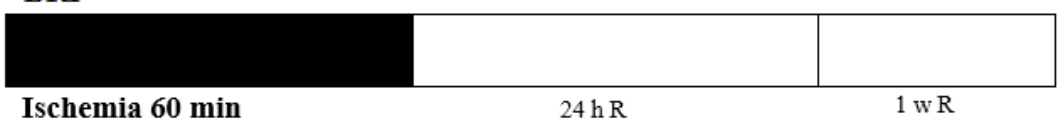

IPo

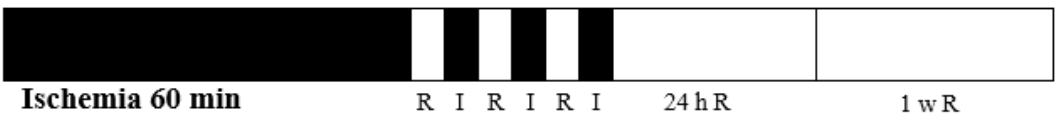

1 cycle of each $10 \mathrm{~s} R / \mathrm{I}$

NEUR SCIENCE

Figure 1. Experimental protocol and timeline applied for examining the effect of IPo after Ischemia (I) and Reperfusion (R)

Sham: Sham-operated rats; BRI rats were subjected to bilateral renal ischemia followed by reperfusion; IPo rats were treated with ischemic postconditioning after BRI (onset of reperfusion).

wire grip test, and shuttle box or Morris water maze (the last two assays were performed in separate groups of study due to the nature of the procedure).

\section{Behavioral experiments}

\section{Open-field test}

The open-field test was used to screen anxiety-like behavior $24 \mathrm{~h}$ and $1 \mathrm{w}$ after reperfusion. The rats were adapted in the experimental room $1 \mathrm{~h}$ before the test, then were placed in the center of the apparatus, i.e., made of a Plexiglas square arena $[90 \times 90 \times 30(\mathrm{H}) \mathrm{cm}]$, its floor was divided into 16 squares, so the field was divided into central and peripheral squares. The vertical and horizontal activities of the animals were observed directly and continuously for $5 \mathrm{~min}$. They then were analyzed using Ethovision software, v. 7.1, a video tracking software to automate the behavioral paradigms (Noldus Information Technology, the Netherlands). The following behavioral components were measured: total distance moved [TDM, $\mathrm{cm}$ ], number of rearing (as a measure of vertical activity), and velocity. At the end of each test, the examined animals were removed from the chamber, and the field was cleaned with a damp cloth (Razavinasab et al., 2013).

\section{Rotarod}

The effects of BRI and postconditioning on motor balance and coordination of the animals by performing ac- celerating rotarod (Hugo Sachs Electronic, Germany) $24 \mathrm{~h}$ and $1 \mathrm{w}$ after reperfusion were observed.

The rotarod performance test measures motor parameters, including motor balance and coordination based on a rotating rod with forced motor activity. The rotarod started from a speed of 10 Revolutions Per Min (RPM) to the maximum speed of 60 RPM. It was divided into 4 equal sections, thus enabling 4 rats to walk on the rod simultaneously. Three trials were performed for each rat (intertrial interval $=30 \mathrm{~min}$ ), with each trial lasting for a total maximum of $300 \mathrm{~s}$. Intervals between the mounting of the rat on the rod and falling off of it were recorded as a measure of motor coordination and balance. The length of time a given animal stays on this rotating rod is known as its balance index (Shabani et al., 2012).

\section{Wire grip test}

To evaluate the muscle strength of the animals, the hanging-wire-grip test was performed 1 week after the operation. The rat was placed in a vertical posture while its forepaws were put in contact with the steel wire $(80$ $\mathrm{cm}$ long, with a diameter of $7 \mathrm{~mm}$ ). The animal was released whenever it grasped the wire. The total time each rat could hang suspended from a wire grid was recorded for three trials with a $30 \mathrm{~min}$ inter-trial interval (Haghani, Shabani, \& Moazzami, 2013). 


\section{Passive Avoidance (PA) learning}

PA learning was selected as the tool for assessing fear learning in BRI rats and the possible effect of postconditioning on $24 \mathrm{~h}$ and $1 \mathrm{w}$ after reperfusion. For this purpose, an apparatus with the dimensions of $100 * 25 * 25$ consisted of two identical illuminated and dark boxes separated by a guillotine door and a stainless rod grid serving as the base. The adaptation phase was followed by a single trial in which the animals were placed in the illuminated compartment. After 10s, the door was opened, and the animal was allowed to go to the dark compartment. After that, the door was closed without electric shock, and after the 20 s, the animal was placed in the cage. The rats without the tendency to enter the dark chamber were excluded. After $30 \mathrm{~min}$ of adaptation, for the learning trial, this procedure was repeated, and animals were given an inescapable foot-shock $(0.5 \mathrm{~mA}, 1.5 \mathrm{~s})$ immediately after entering the darkroom. This procedure was repeated until the animal did not enter the dark box. The number of shocks received was recorded in this phase. The retention tests were conducted $24 \mathrm{~h}$ after the training phase (without shock) to evaluate memory. The latency time (cut off: $300 \mathrm{sec}$ ) to enter the dark compartment as retention time [Step-Through Latency (STL)] was recorded (Abbassian et al., 2016).

\section{Morris Water Maze (MWM)}

The rats were tested by an MWM as previously described (Aghaei, Shabani, Doustar, Nazeri, \& Dehpour, 2014). The test chamber was a circular tank (140 cm diameter, $45 \mathrm{~cm}$ height), surrounded by extra-tank visual cues. A visible or submerged platform ( $15 \mathrm{~cm}$ wide, 35 $\mathrm{cm}$ height) was placed $1.5 \mathrm{~cm}$ above or below the water surface. Water temperature was maintained at $21-23^{\circ} \mathrm{C}$. Rats' behavior was recorded with the Ethovision system. The following parameters were computed for each animal: total distance and time spent to reach the platform in three consecutive trials, the number of crosses in the correct quadrant in the retention phase, percentage of the time, and distance traveled in the correct quadrant. Each rat underwent three blocks of trials in the training phase, each including four trials (inter-trial interval $=30$ s). In each trial, animals were put in one of the 4 quadrants facing the maze. The examined animals were allowed to swim the 60 s to find the platform, and if they did not find it, they were put on the platform by the examiner. After $30 \mathrm{~s}$, the rat was again put to trial. After $2 \mathrm{~h}$ of the last block, the rats underwent a probe trial during which the platform was removed from the tank and the number of crosses in the correct quadrant and total time spent in the target quadrant was recorded and analyzed per rat (Shabani, et sl., 2012).

\section{Molecular experiment}

\section{Tissue dissection and preparation for Western blot}

The rats were divided into sham, BRI, and IPo groups for the molecular experiment, decapitated 24h after surgery. All of the rats were anesthetized with atmospheric $\mathrm{CO}_{2}$. After decapitation, the brains were rapidly extracted and placed on ice. Both whole hippocampi were freshly harvested and placed in a microtube and stored at -80 until homogenization for further western blot assay.

\section{BDNF immunoblot analysis}

The dissected hippocampus tissues were homogenized in ice-cold buffer containing $10 \mathrm{mM}$ Tris- $\mathrm{HCl}(\mathrm{pH}=7.4)$, $1 \mathrm{mM}$ EDTA, $0.1 \%$ SDS, $0.1 \%$ Na-deoxycholate, $1 \%$ NP-40 with protease inhibitors $(1 \mathrm{mM}$ phenylmethylsulfonyl fluoride, $2.5 \mu \mathrm{g} / \mathrm{mL}$ of leupeptin, $10 \mu \mathrm{g} / \mathrm{mL}$ of aprotinin) and $1 \mathrm{mM}$ sodium orthovanadate (a phosphatase inhibitor). The homogenate was centrifuged at 15,000 RPM for 20 min at $4^{\circ} \mathrm{C}$. The resulting supernatant was retained as the whole-cell fraction. Protein concentrations were measured using the Bradford method (BioRad Laboratories, Muenchen, Germany). Equal amounts of protein were resolved electrophoretically on a 9\% SDS Polyacrylamide Gel Electrophoresis (SDS-PAGE) SDSPAGE gel and transferred to PVDF (polyvinylidenefluoride) membranes. After blocking with 5\%, non-fat dried milk in Tris-buffered saline with Tween 20 (blocking buffer, TBS-T, $150 \mathrm{mM} \mathrm{NaCl}, 20 \mathrm{mM}$ Tris-HCl, $\mathrm{pH}$ 7.5, $0.1 \%$ Tween 20 ) for $2 \mathrm{~h}$, at room temperature and then, the membranes were incubated overnight with a primary rabbit polyclonal antibody for BDNF (1:1000, sc-20981; Santa Cruz Biotechnology, Santa Cruz, USA) at $4^{\circ} \mathrm{C}$. After washing in TBS-T buffer ( 3 times for 5 min each, at room temperature), the blots were incubated for $2 \mathrm{~h}$ at room temperature with an anti-rabbit IgG secondary antibody conjugated with horseradish peroxidase $(1: 15,000$; GE Healthcare Bio-Sciences). The primary and secondary antibodies were diluted in blocking buffer. The antibody-antigen complexes were revealed using the ECL system (Amersham Biosciences). Images were captured on a Gel Doc imaging system (Bio-Rad, Hercules, CA, US) converted to a tiff file. Lab Work analyzing software (UVP, UK) was used to analyze the intensity of the expression. $\beta$-actin immunoblotting (antibody from Cell Signaling Technology, INC. Beverly, MA, USA; 1:1000) was used to control loading. The timeline applied for the experimental protocol has been indicated in Figure 2.

Statistical analysis was performed in SPSS. All data were expressed as Mean \pm SEM. Analysis of Variance 


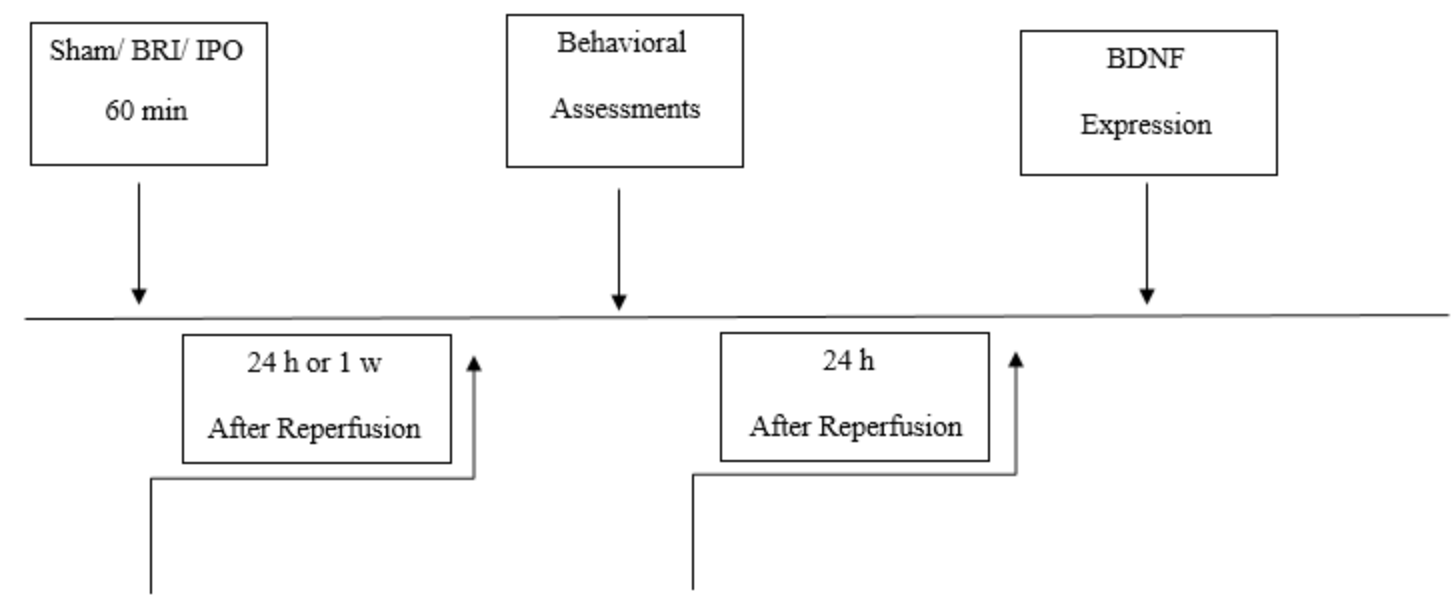

Figure 2. The timeline applied for the experimental protocol.

NEUR SCIENCE

(ANOVA) followed by Tukey's post-hoc analysis was used to compare the differences between the study groups. Repeated-measures ANOVA was used to analyze the data of the MWM task in the learning phase. The band density values were expressed as BDNF/ $\beta$ actin ratio for each sample. The mean differences for the study groups were compared using one-way ANOVA, followed by the Newman-Keuls test. $\mathrm{P}<0.05$ was considered significant.

\section{Results}

\section{Open field test}

The open field has been used to investigate locomotion and anxiety-related behaviors. Rats were subjected to 60 min of renal ischemia followed by reperfusion presented no significant differences in all parameters (velocity, rearing number, \& total distance moved) measured in this test $24 \mathrm{~h}$ after operation ( $\mathrm{P}>0.05$, Figure $3-\mathrm{A}, \mathrm{B}$, and $\mathrm{C}$ ). Moreover, an open field test also was performed 1 week after surgery. There was no significant alteration in mentioned parameters 1 week after surgery (Figure 4-A, B, \& C).

The effect of BRI on balance function, motor learning, and muscle strength

Compared with the sham group, BRI reduced duration on the rod $24 \mathrm{~h}$ after surgery $(\mathrm{P}<0.01)$. Postconditioning rats had no significant difference with sham and BRI groups $(\mathrm{P}>0.05)$ (Figure 5). No significant difference in duration on the rod was observed between the groups of study 1 week after reperfusion $(\mathrm{P}>0.05)$ (Figure 6). BRI animals showed reduced muscle strength compared to the postconditioning group 1 week after reperfusion $(\mathrm{P}<0.05$, Figure 7$)$. Postconditioning could significantly reverse this effect of BRI.
The effect of BRI and IPo on PA learning 24h after reperfusion

There was no significant difference in the number of shocks received among the three groups $(\mathrm{P}>0.05$, Figure 8-A). BRI rats had impairment in memory retrieval compared to the sham group ( $\mathrm{P}<0.001$, ANOVA); postconditioning could reverse this impairment in BRI rats $(\mathrm{P}<0.05$, ANOVA) (Figure 8-B).

The effect of BRI and IPo on PA learning 1 week after reperfusion

No significant alteration in the parameters measured was observed amongst three groups of study 1 week after reperfusion $(\mathrm{P}>0.05$, Figure $9-\mathrm{A} \& \mathrm{~B})$.

The effect of BRI and IPo on spatial learning 1 week after reperfusion

There were no significant differences in the parameters measured across blocks of trials (Figure 10-A \&C) and probe trial (Figure 10-D \& F) between groups in all periods, indicating that BRI and IPo did not influence the spatial learning.

\section{BDNF protein expression}

Next, we sought to identify a potential molecular mechanism that underlies memory impairments. We evaluate the expression of BDNF 24h after reperfusion because the IR-induced memory dysfunction was observed just at this time point. As per Figure 11, IR rats indicated a decreased hippocampal BDNF protein expression level than the sham-operated group $(\mathrm{P}<0.05)$. Surprisingly, the postconditioning situation could significantly $(\mathrm{P}<0.05)$ prevent the decreasing effect of renal IRI on the hippocampal BDNF expression (Figure 11). Therefore, the 

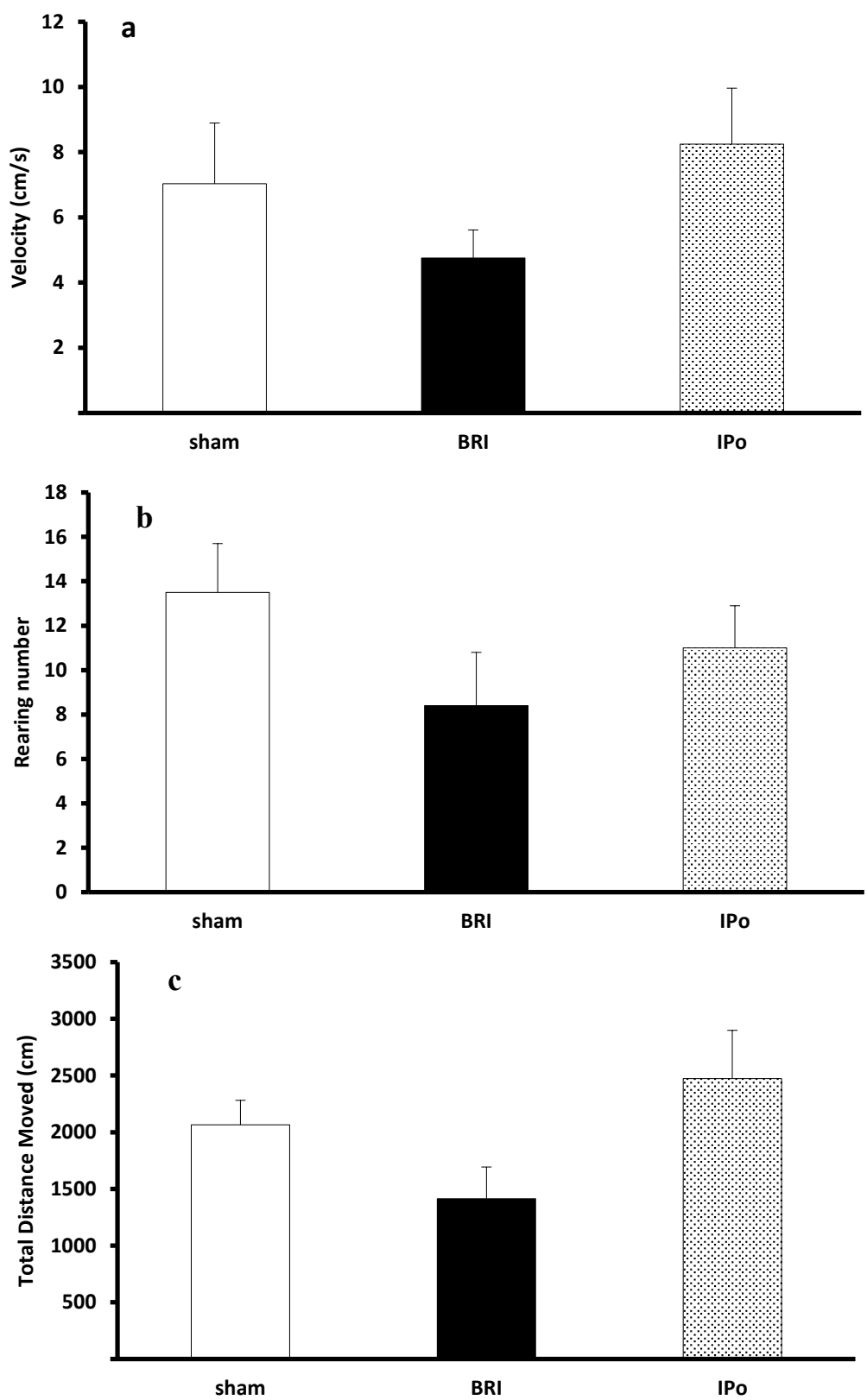

Figure 3. The effects of postconditioning on locomotion and anxiety-related behaviors $24 \mathrm{~h}$ after reperfusion

A: There were no significant differences in velocity; B: Rearing number ; and C: Total distance moved among groups.

present results indicated that the significant down-regulation of the BDNF protein in BRI rats was prevented by inducing renal ischemic postconditioning.

\section{Discussion}

Ischemia causes tissue damage in various clinical situations, such as acute infarctions or hypoperfusion, and the restoration of suitable blood flow is the primary treatment. Remote ischemic conditioning is an approach of conditioning that is not the target organ, but a more accessible tissue is submitted to a conditioning stimulus.

We observed that $1 \mathrm{~h}$ of BRI, as a model of acute kidney injury in rats, impairs memory and balance function $24 \mathrm{~h}$ after reperfusion and muscle strength of the animals $1 \mathrm{w}$ after reperfusion. Postconditioning indicated a promising effect against these impairments induced by BRI. Moreover, we observed no significant memory impairment and balanced disability in the BRI group, compared to the other groups $1 \mathrm{w}$ after the operation. 

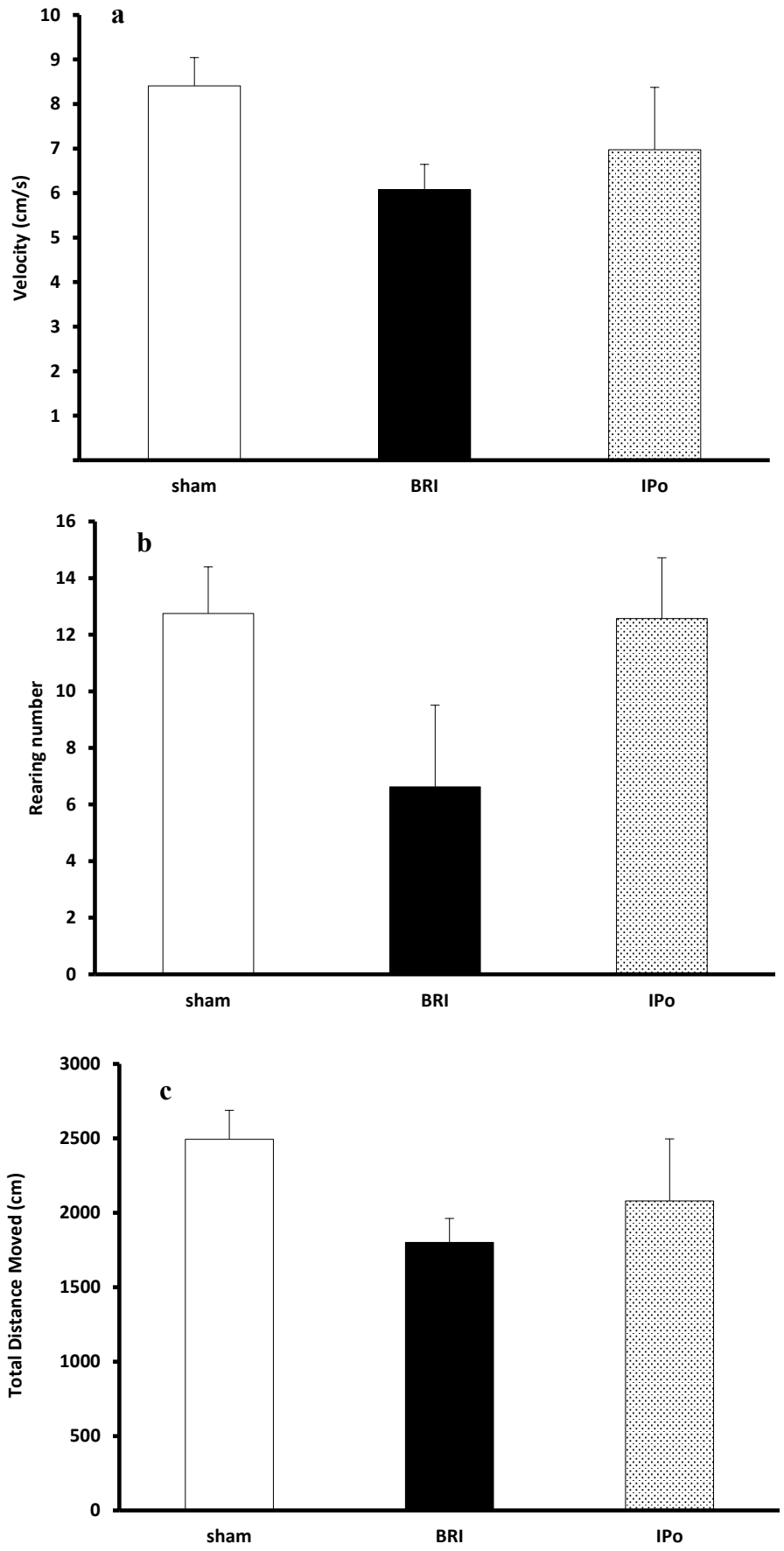

Figure 4. The effects of postconditioning on locomotion and anxiety-related behaviors $1 \mathrm{w}$ after reperfusion

A-C: There were no significant differences in velocity, rearing number, and total distance moved between the groups.

The high morbidity and mortality in patients with $\mathrm{AKI}$ and the non-existence of effective therapeutic modalities necessitate strategies to alleviate the impact of kidney injury on distant organs. Ischemic renal tissue's reperfusion (sudden restoration of blood flow) is highly harmful, especially at ischemia. The reperfusion phase initiates a wide range of cellular events responsible for transendothelial migration of inflammatory cells, tissue edema, necrotic and apoptotic cell death (Edelstein, Ling, \& Schrier, 1997). Thus, interventions given only at the beginning of reperfusion can reduce post-ischemic injury (Zhao, 2010). 


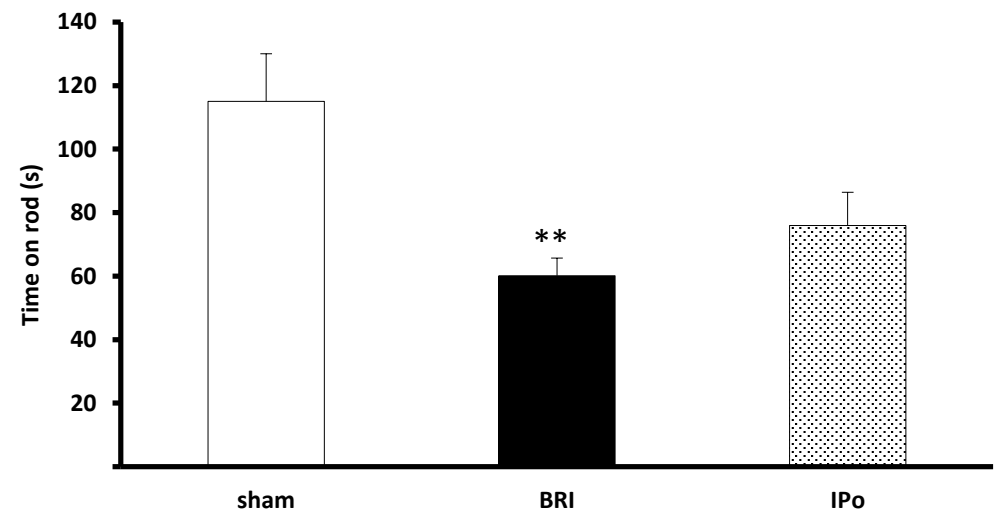

NEUR:SCIENCE

Figure 5. The effects of postconditioning on balance function $24 \mathrm{~h}$ after reperfusion

Rats of BRI had a decreased time on rod $24 \mathrm{~h}$ after ischemia, which shows balance impairments; ** $\mathrm{P}<0.01$ as compared to the sham group.

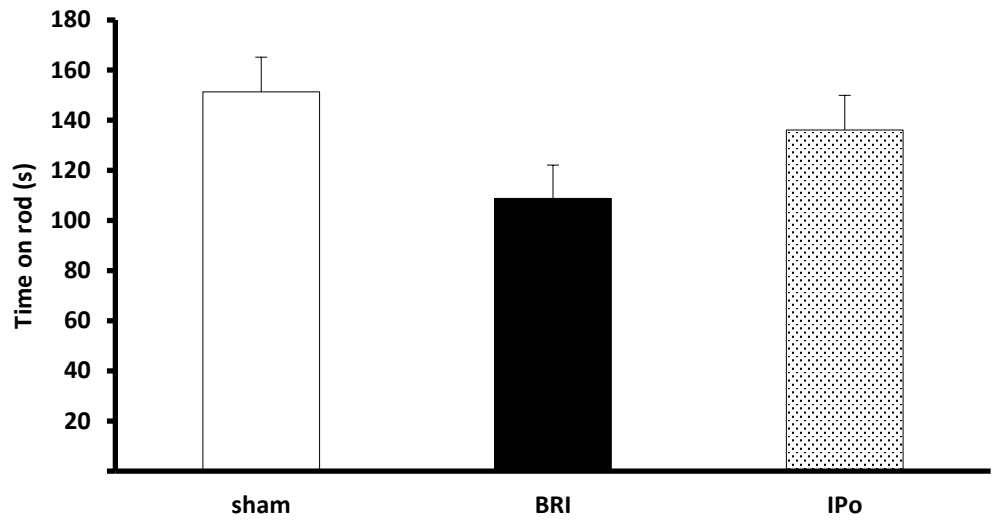

Figure 6. The effects of postconditioning on balance function $1 \mathrm{w}$ after reperfusion

There was no significant difference in time on rod amongst the three groups.

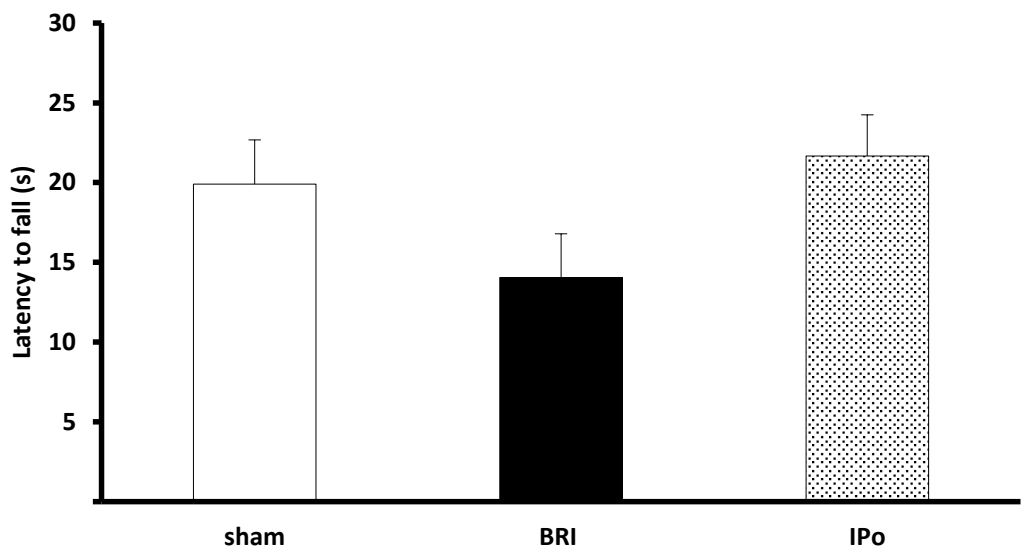

Figure 7. The effects of postconditioning on muscle strength $1 \mathrm{w}$ after reperfusion 

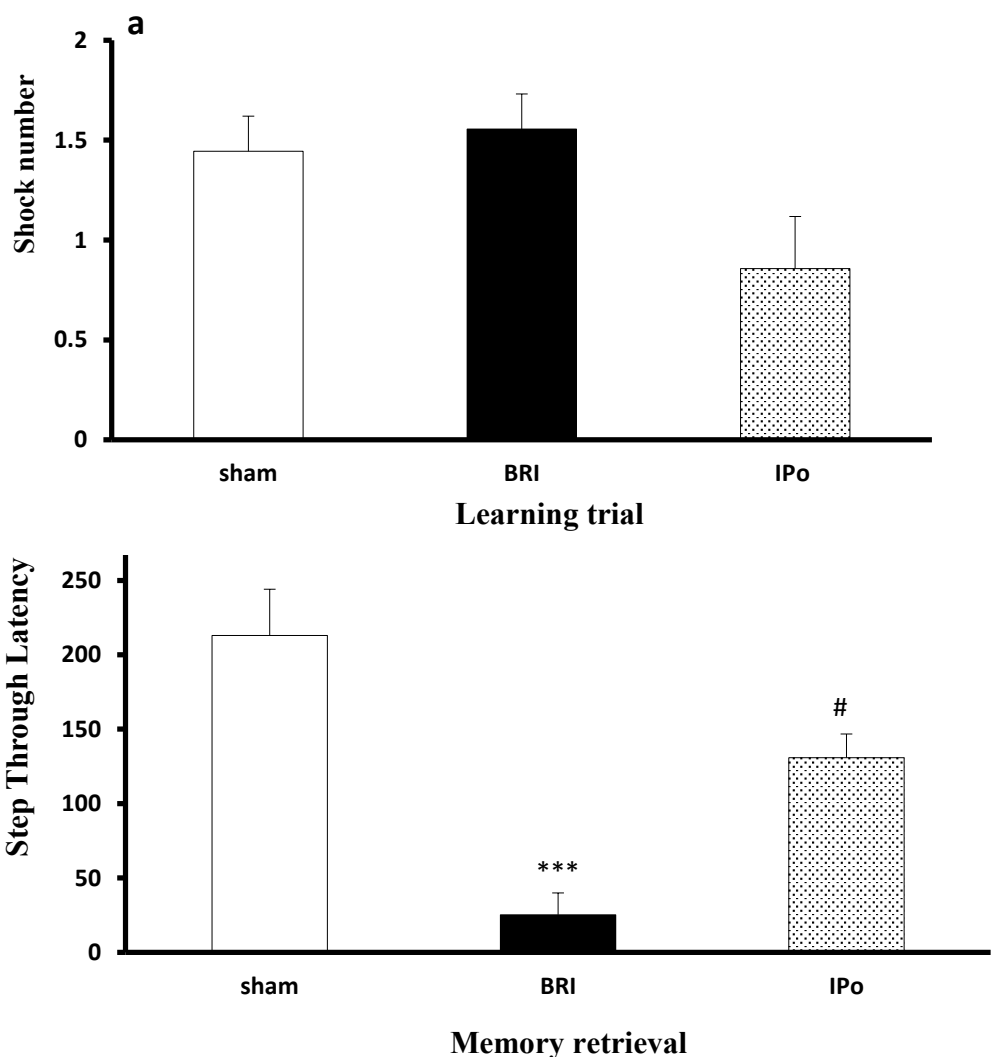

NEUR SCIENCE

Figure 8. The effects of BRI and postconditioning on the fear learning in passive avoidance learning paradigm 24h after reperfusion

A: The number of shocks received in the training day was not altered amongst the three groups, indicating that fear learning is not changed between the three study groups; B: Decreased Step-Through Latency (STL) in BRI animals demonstrates an impaired fear memory. Postconditioning significantly reduced this impairment of BRI on fear memory; ${ }^{* * *} \mathrm{P}<0.001$, as compared to the sham group; ${ }^{\# P}<0.05$, compared to the BRI group.

BRI reliably induced balance and muscle strength impairments in the behavioral tasks employed in the present study. Previous studies revealed that the alterations in locomotor activity are related to the ischemic damage of CA1 area of the hippocampus in the open-field test (Chandler, DeLeo, \& Carney, 1985; Gerhardt \& Boast, 1988; Liu et al., 2008; Skelly, Hennessy, Dansereau, \& Cunningham, 2013; Wang \& Corbett, 1990) a region which is involved in anxiety and depression (Heldt, Stanek, Chhatwal, \& Ressler, 2007). Increased circulating inflammatory cytokines and the number of pyknotic neuronal cells in the hippocampus have been indicated due to AKI (Liu et al., 2008; Skelly et al., 2013). No significant difference was observed between total distances moved, velocity, and rearing numbers in both time points assessed by open field test $24 \mathrm{~h}$ and $1 \mathrm{w}$ after reperfusion.

The current study confirmed that bilateral renal ischemia followed by $24 \mathrm{~h}$ of reperfusion resulted in memory impairment, i.e., assessed by a PA learning test. Postconditioning could improve this impairment in BRI rats.
BRI followed by $1 \mathrm{w}$ of reperfusion couldn't impair PA learning, and no significant difference was observed between the groups. Several studies on alterations in brain function following cerebral ischemia verify impairments in motor coordination, learning, and memory abilities (Norio et al., 1990; Tahamtan et al., 2013; Yan, Hou, Wu, Liu, \& Zhou, 2007).

The total distances moved, and velocity is not significant between groups in different time points; therefore, it can indicate that the memory defect shown in the PA test is not due to the impaired ability of animals to move freely.

One promising finding of the previous studies is postconditioning. The term "postconditioning" refers to intermittent interruptions of blood flow at the onset of reperfusion which can activate signaling pathways and effectors (Zhao et al., 2003). However, the detailed mechanisms underlying these actions remain to be determined. To our knowledge, for the first time, we report that postconditioning protects some aspects of brain 

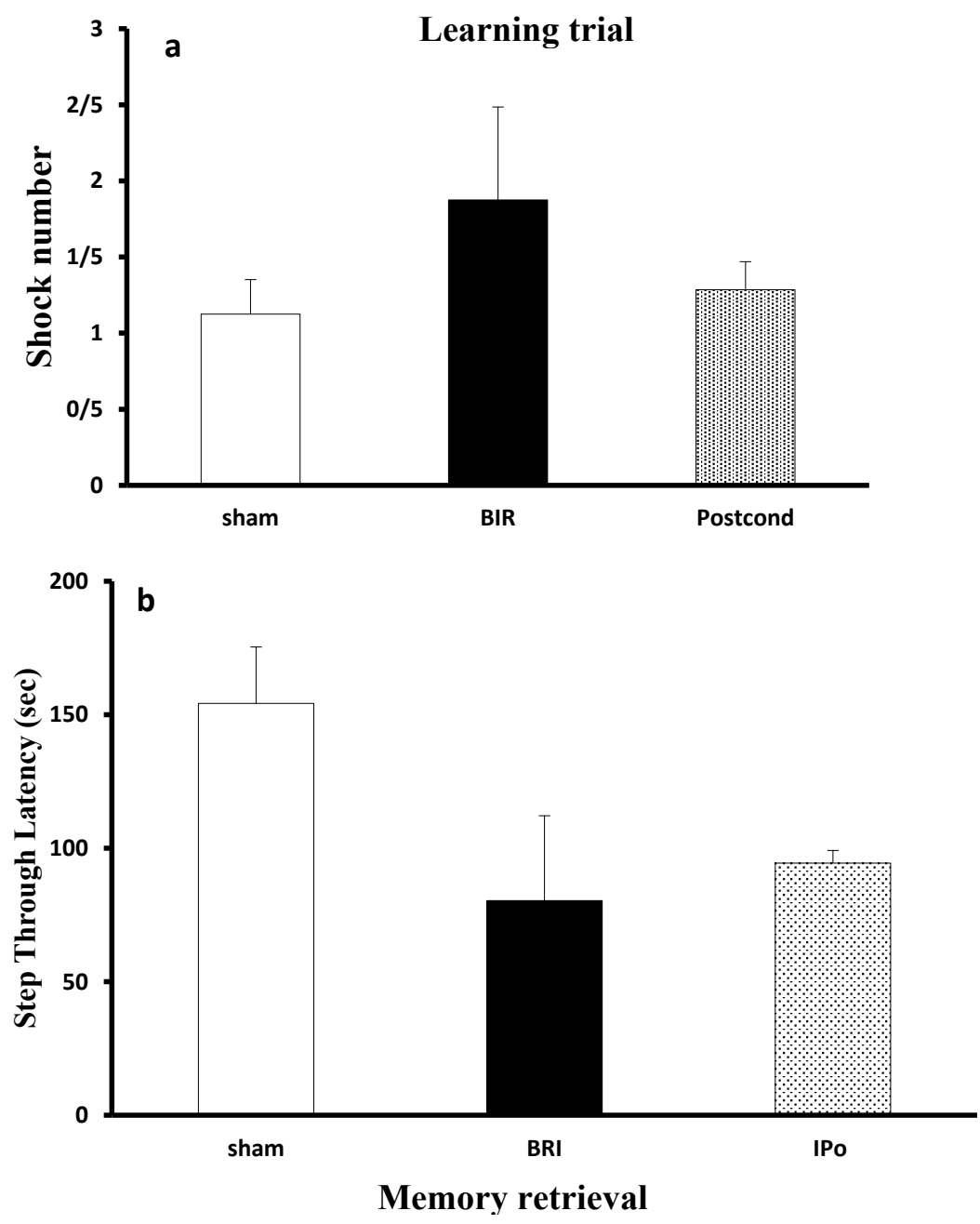

NEUR SCIENCE

Figure 9. The effects of BRI and postconditioning on fear learning in passive avoidance learning paradigm $1 \mathrm{w}$ after reperfusion

A: There was no significant alteration in the number of shocks received in training, which indicates that fear learning is not altered amongst experimental groups; B: Step-Through Latency (STL) was not altered between the three groups, implying that fear memory is not altered among the three study groups.

function against reperfusion injury induced by bilateral renal ischemia. Remote ischemic conditioning activates protective pathways in distant organs, such as the brain, heart, and kidney, representing an exciting new neuroprotection pattern. The exact mechanism of signal transmission from the periphery to the brain is unknown; however, humoral factors and an intact nervous system play critical roles.

One of the critical objectives of the experiments was to examine the effect of renal IRI and renal IRI Plus postconditioning on hippocampal BDNF level. Immunoblotting data indicated that postconditioning preserved BDNF protein level in the hippocampus region of BRI rats. BDNF, a crucial trophic factor in synaptic plasticity (Cunha, Brambilla, \& Thomas, 2010), is present in high concentration in the hippocampus and cerebral cortex (Cotman \& Ber- chtold, 2002). BDNF plays a crucial role in hippocampaldependent learning and memory. It also may indicate a promising neuromodulatory therapeutic agent, increasing the survival of neurons, regeneration, and differentiation (Bella, Lin, Cagiannos, \& Lue, 2008; Cotman \& Berchtold, 2002; Hariri et al., 2003). Furthermore, BRI-induced changes in PA learning and memory seem to correlate with the decrease in hippocampal BDNF level.

A growing body of literature demonstrates that BDNF has not only potent neuroprotective effects but also is a strong inducer of recovery after various types of ischemic lesions (Kiprianova, Sandkühler, Schwab, Hoyer, \& Spranger, 1999; Schäbitz et al., 2004; Schäbitz, Schwab, Spranger, \& Hacke, 1997; Schäbitz, Sommer, Zoder, Kiessling, Schwaninger, \& Schwab, 2000; Wu \& Pardridge, 1999). 

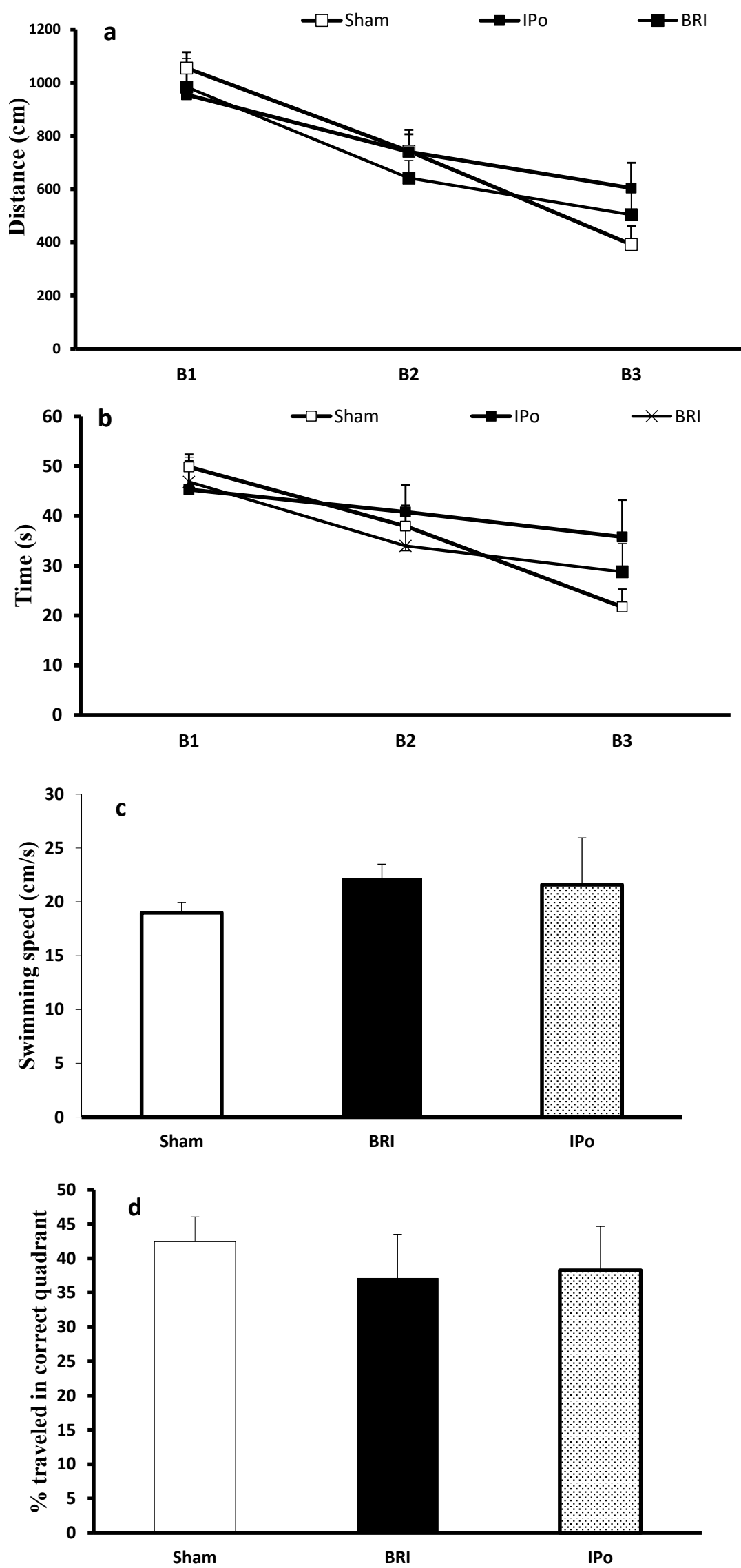

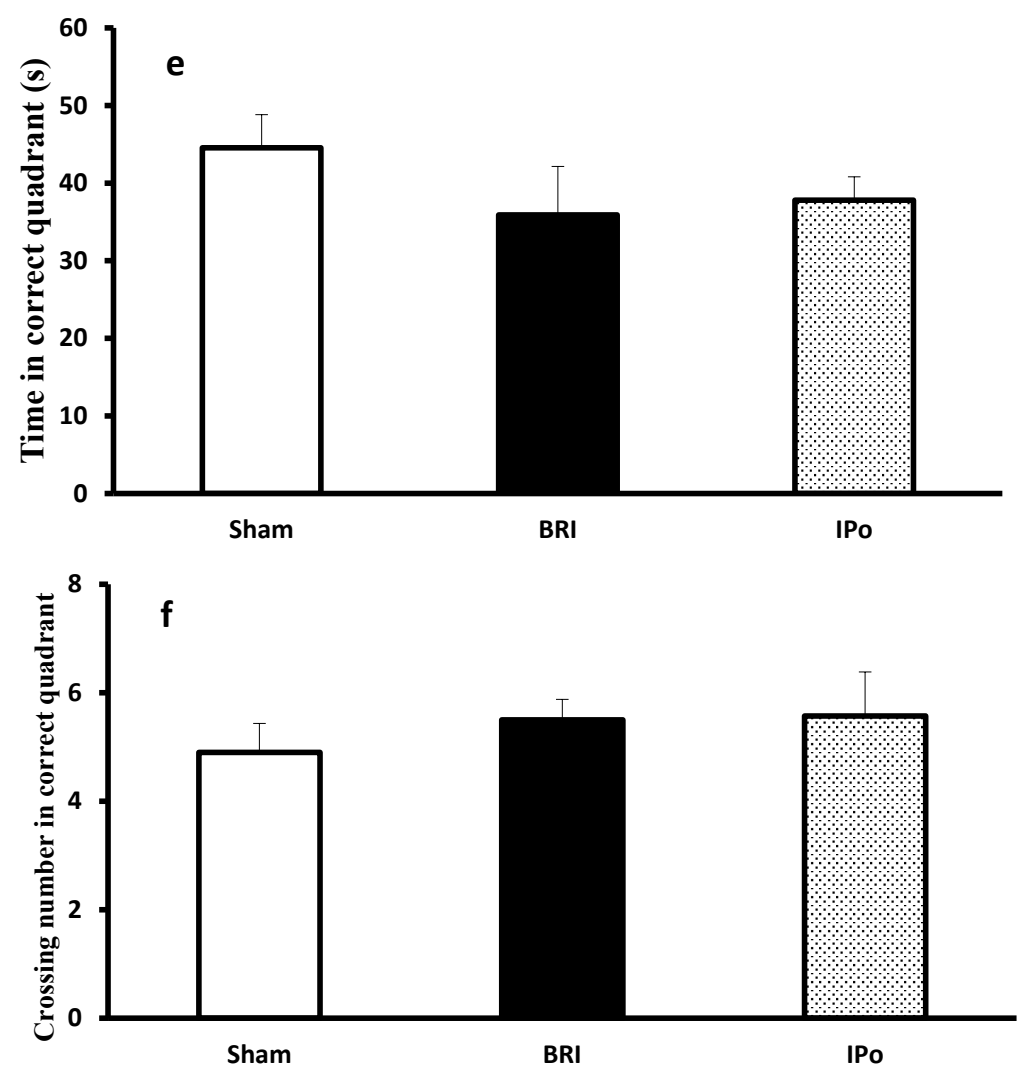

Figure 10. The effects of BRI and postconditioning on spatial learning and memory $1 \mathrm{w}$ after reperfusion

There was no significant difference between parameters measured among the three groups of study $(\mathrm{P}>0.05)$.

\section{Sham BRI IPO}

$\beta$-Actin $42 \mathrm{KDa}$

$\mathrm{BDNF} 14 \mathrm{KDa}$
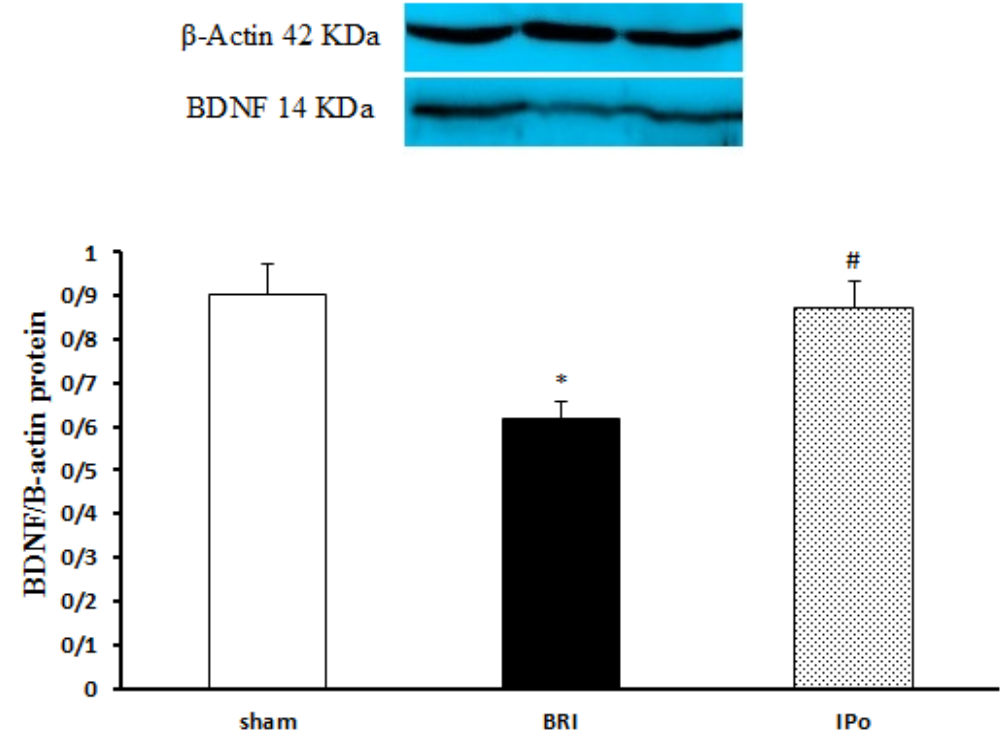

NEUR SCIENCE

Figure 11. The Effects of postconditioning on the BDNF protein levels in the hippocampus of rats. BRI reduced the BDNF protein levels in the hippocampus of the studied rats

Postconditioning improved this deficit. Each value point in the graphs represents the Mean \pm SEM ( $n=5-7$ rats/group). $\beta$-Actin was used as an internal control; ${ }^{*} \mathrm{P}<0.05$, compared to the sham group; ${ }^{\mathrm{P}} \mathrm{P}<0.05$, compared to the BRI group. 
The present study data agree with the previous studies. Seifi et al. reported that postconditioning protected the liver, as a remote organ, from renal IRI may be through reducing oxidative stress markers (Seifi et al., 2014). Additionally, another study indicated that postconditioning reduced the systemic damage intensity after a small intestinal ischemic reperfusion episode (Onody et al., 2012).

\section{Conclusion}

The current study results suggested that AKI triggers distant organ dysfunction and postconditioning protects some aspects of brain function, as a remote organ from the renal ischemia-reperfusion injury. These beneficial effects of postconditioning against IR-induced memory impairment may be associated with preventing IR-induced hippocampal BDNF down-regulation. Moreover, the present study adds to the literature supporting the concept that modifying reperfusion conditions at the early moments may be a valuable strategy to reduce injuries induced by ischemia-reperfusion.

\section{Ethical Considerations}

\section{Compliance with ethical guidelines}

This study was approved by the ethical committee of the Kerman Medical University.

\section{Funding}

The study was funded by Kerman Neuroscience Research Center.

\section{Authors' contributions}

All authors equally contributed to preparing this article.

\section{Conflict of interest}

The authors declare no conflict of interest.

\section{Refrences}

Abbassian, H., Esmaeili, P., Tahamtan, M., Aghaei, I., Vaziri, Z., \& Sheibani, V., et al. (2016). Cannabinoid receptor agonism suppresses tremor, cognition disturbances and anxiety-like behaviors in a rat model of essential tremor. Physiology \& Behavior, 164(PartA), 314-20. [DOI:10.1016/j. physbeh.2016.06.013] [PMID]

Aghaei, I., Shabani, M., Doustar, N., Nazeri, M., \& Dehpour, A (2014). Peroxisome proliferator-activated receptor- $\gamma$ activa- tion attenuates motor and cognition impairments induced by bile duct ligation in a rat model of hepatic cirrhosis. Pharmacology Biochemistry and Behavior, 120, 133-9. [DOI:10.1016/j. pbb.2014.03.002] [PMID]

Arieff, A. I., \& Massry, S. G. (1974). Calcium metabolism of brain in acute renal failure. Effects of uremia, hemodialysis, and parathyroid hormone. The Journal of Clinical Investigation, 53(2), 387-92. [DOI:10.1172/JCI107571] [PMID] [PMCID]

Arieff, A. I., Massry, S. G., Barrientos, A., \& Kleeman, C. R (1973). Brain water and electrolyte metabolism in uremia: Effects of slow and rapid hemodialysis. Kidney International, 4(3), 177-87. [DOI:10.1038/ki.1973.100] [PMID]

Bella, A. J., Lin, G., Cagiannos, I., \& Lue, T. F. (2008). Emerging neuromodulatory molecules for the treatment of neurogenic erectile dysfunction caused by cavernous nerve injury. Asian Journal of Andrology, 10(1), 54-59. [DOI:10.1111/j.17457262.2008.00368.x] [PMID]

Chandler, M. J., DeLeo, J., \& Carney, J. M. (1985). An unanesthetized-gerbil model of cerebral ischemia-induced behavioral changes. Journal of Pharmacological Methods, 14(2), 137-46. [DOI:10.1016/0160-5402(85)90051-8] [PMID]

Cotman, C. W., \& Berchtold, N. C. (2002). Exercise: A behavioral intervention to enhance brain health and plasticity. Trends in Neurosciences, 25(6), 295-301. [DOI:10.1016/S01662236(02)02143-4][PMID]

Cunha, C., Brambilla, R., \& Thomas, K. L. (2010). A simple role for BDNF in learning and memory? Frontiers in Molecular Neuroscience, 3, 1. [DOI:10.3389/neuro.02.001.2010] [PMID] [PMCID]

Deftereos, S., Giannopoulos, G., Tzalamouras, V., Raisakis, K., Kossyvakis, C., \& Kaoukis, A., et al. (2013). Renoprotective effect of remote ischemic post-conditioning by intermittent balloon inflations in patients undergoing percutaneous coronary intervention. Journal of the American College of Cardiology, 61(19), 1949-55. [DOI:10.1016/j.jacc.2013.02.023] [PMID]

Edelstein, C. L., Ling, H., \& Schrier, R. W. (1997). The nature of renal cell injury. Kidney International, 51(5), 1341-51. [DOI:10.1038/ki.1997.183] [PMID]

Gerhardt, S. C., \& Boast, C. A. (1988). Motor activity changes following cerebral ischemia in gerbils are correlated with the degree of neuronal degeneration in hippocampus. Behavioral Neuroscience, 102(2), 301-3. [DOI:10.1037/0735-7044.102.2.301] [PMID]

Guo, Q., Du, X., Zhao, Y., Zhang, D., Yue, L., \& Wang, Z. (2014) Ischemic postconditioning prevents renal ischemia reperfusion injury through the induction of heat shock proteins in rats. Molecular Medicine Reports, 10(6), 2875-81. [DOI:10.3892/ mmr.2014.2641] [PMID] [PMCID]

Haghani, M., Shabani, M., \& Moazzami, K. (2013). Maternal mobile phone exposure adversely affects the electrophysiological properties of Purkinje neurons in rat offspring. Neuroscience, 250, 588-98. [DOI:10.1016/j.neuroscience.2013.07.049] [PMID]

Hariri, A. R., Goldberg, T. E., Mattay, V. S., Kolachana, B. S., Callicott, J. H., \& Egan, M. F., et al. (2003). Brain-derived neurotrophic factor val66met polymorphism affects human memory-related hippocampal activity and predicts memory performance. The Journal of Neuroscience, 23(17), 6690-4. [DOI:10.1523/JNEUROSCI.23-17-06690.2003] [PMID] [PMCID] 
Hassoun, H. T., Grigoryev, D. N., Lie, M. L., Liu, M., Cheadle, C., \& Tuder, R. M., et al. (2007). Ischemic acute kidney injury induces a distant organ functional and genomic response distinguishable from bilateral nephrectomy. American Journal of Physiology-Renal Physiology, 293(1), F30-40. [DOI:10.1152/ajprenal.00023.2007] [PMID]

Heldt, S. A., Stanek, L., Chhatwal, J. P., \& Ressler, K. J. (2007). Hippocampus-specific deletion of BDNF in adult mice impairs spatial memory and extinction of aversive memories. Molecular Psychiatry, 12(7), 656-70. [DOI:10.1038/ sj.mp.4001957] [PMID] [PMCID]

Hussein, A. A. M., Barakat, N., Awadalla, A., \& Shokeir, A. A (2012). Systemic and renal haemodynamic changes in renal schemia/reperfusion injury: Impact of erythropoietin. Canadian Journal of Physiology and Pharmacology, 90(11), 1535-43. [DOI:10.1139/y2012-120] [PMID]

Khatri, M., Himmelfarb, J., Adams, D., Becker, K., Longstreth, W. T., \& Tirschwell, D. L. (2014). Acute kidney injury is associated with increased hospital mortality after stroke. Journal of Stroke and Cerebrovascular Diseases, 23(1), 25-30. [DOI:10.1016/j. jstrokecerebrovasdis.2012.06.005] [PMID] [PMCID]

Kin, H., Zatta, A. J., Lofye, M. T., Amerson, B. S., Halkos, M. E., \& Kerendi, F., et al. (2005). Postconditioning reduces infarct size via adenosine receptor activation by endogenous adenosine. Cardiovascular Research, 67(1), 124-33. [DOI:10.1016/j.cardiores.2005.02.015] [PMID]

Kin, H., Zhao, Z. Q., Sun, H.-Y., Wang, N.-P., Corvera, J. S., \& Halkos, M. E., et al. (2004). Postconditioning attenuates myocardial ischemia-reperfusion injury by inhibiting events in the early minutes of reperfusion. Cardiovascular Research, 62(1), 74-85. [DOI:10.1016/j.cardiores.2004.01.006] [PMID]

Kinsey, G. R., Li, L., \& Okusa, M. D. (2008). Inflammation in acute kidney injury. Nephron Experimental Nephrology, 109(4), e102-e107. [DOI:10.1159/000142934] [PMID] [PMCID]

Kiprianova, I., Sandkühler, J., Schwab, S., Hoyer, S., \& Spranger, M. (1999). Brain-derived neurotrophic factor improves longterm potentiation and cognitive functions after transient forebrain ischemia in the rat. Experimental Neurology, 159(2), 511-9. [DOI:10.1006/exnr.1999.7109] [PMID]

Liu, K. X., Li, Y. S., Huang, W. Q., Chen, S. Q., Wang, Z. X., \& Liu, J. X., et al. (2009). Immediate postconditioning during reperfusion attenuates intestinal injury. Intensive Care Medicine, 35(5), 933-42. [DOI:10.1007/s00134-009-1428-1] [PMID]

Liu, M., Liang, Y., Chigurupati, S., Lathia, J. D., Pletnikov, M. \& Sun, Z., et al. (2008). Acute kidney injury leads to inflammation and functional changes in the brain. Journal of the American Society of Nephrology, 19(7), 1360-70. [DOI:10.1681/ ASN.2007080901] [PMID] [PMCID]

Liu, X., Chen, H., Zhan, B., Xing, B., Zhou, J., \& Zhu, H., et al (2007). Attenuation of reperfusion injury by renal ischemic postconditioning: The role of NO. Biochemical and Biophysical Research Communications, 359(3), 628-34. [DOI:10.1016/j. bbrc.2007.05.129] [PMID]

Lønborg, J., Kelbæk, H., Vejlstrup, N., Jørgensen, E., Helqvist, S., \& Saunamäki, K., et al. (2010). Cardioprotective effects of ischemic postconditioning in patients treated with primary percutaneous coronary intervention, evaluated by magnetic resonance. Circulation Cardiovascular Interventions, 3(1), 34-41. [DOI:10.1161/CIRCINTERVENTIONS.109.905521] [PMID]
Melo, C. V., Okumoto, S., Gomes, J. R., Baptista, M. S., Bahr, B. A., \& Frommer, W. B., et al. (2013). Spatiotemporal resolution of BDNF neuroprotection against glutamate excitotoxicity in cultured hippocampal neurons. Neuroscience, 237, 66-86. [DOI:10.1016/j.neuroscience.2013.01.054] [PMID]

Nongnuch, A., Panorchan, K., \& Davenport, A. (2014). Brainkidney crosstalk. Crit Care, 18(3), 225. [DOI:10.1186/cc13907] [PMID] [PMCID]

Norio, H., Hiroshi, W., Nobuhide, A., Mitsue, K., Jiro, I., \& Yushiro, T. (1990). Cerebral ischemia model with conscious mice: Involvement of NMDA receptor activation and derangement of learning and memory ability. Journal of Pharmacological Methods, 23(4), 311-27. [DOI:10.1016/0160-5402(90)90059-T] [PMID]

Onody, P., Rosero, O., Kovacs, T., Gabbais, D., Hegedüs, V. \& Lotz, G., et al. (2012). Postconditioning--effective method against distant organ dysfunction? Magyar Sebeszet, 65(4), 222-9. [DOI:10.1556/maseb.65.2012.4.9] [PMID]

Penna, C., Tullio, F., Moro, F., Folino, A., Merlino, A., \& Pagliaro, P. (2010). Effects of a protocol of ischemic postconditioning and/or captopril in hearts of normotensive and hypertensive rats. Basic Research in Cardiology, 105(2), 181-92. [DOI:10.1007/ s00395-009-0075-6] [PMID]

Ratliff, B. B., Rabadi, M. M., Vasko, R., Yasuda, K., \& Goligorsky, M. S. (2013). Messengers without borders: Mediators of systemic inflammatory response in AKI. Journal of the American Society of Nephrology, 24(4), 529-36. [DOI:10.1681/ ASN.2012060633] [PMID]

Razavinasab, M., Shamsizadeh, A., Shabani, M., Nazeri, M., Allahtavakoli, M., \& Asadi-Shekaari, M., et al. (2013). Pharmacological blockade of TRPV1 receptors modulates the effects of 6-OHDA on motor and cognitive functions in a rat model of parkinson's disease. Fundamental \& Clinical Pharmacology, 27(6), 632-40. [DOI:10.1111/fcp.12015] [PMID]

Ren, C., Gao, X., Niu, G., Yan, Z., Chen, X., \& Zhao, H. (2008) Delayed postconditioning protects against focal ischemic brain injury in rats. PloS one, 3(12), e3851. [DOI:10.1371/journal.pone.0003851] [PMID] [PMCID]

Schäbitz, W. R., Berger, C., Kollmar, R., Seitz, M., Tanay, E., \& Kiessling, M., et al. (2004). Effect of brain-derived neurotrophic factor treatment and forced arm use on functional motor recovery after small cortical ischemia. Stroke, 35(4), 992-7. [DOI:10.1161/01.STR.0000119754.85848.0D] [PMID]

Schäbitz, W. R., Schwab, S., Spranger, M., \& Hacke, W. (1997) Intraventricular brain-derived neurotrophic factor size after focal cerebral ischemia in rats. Journal of Cerebral Blood Flow $\mathcal{E}$ Metabolism, 17(5), 500-6. [DOI:10.1097/00004647-19970500000003] [PMID]

Schäbitz, W. R., Sommer, C., Zoder, W., Kiessling, M. Schwaninger, M., \& Schwab, S. (2000). Intravenous brainderived neurotrophic factor reduces infarct size and counterregulates Bax and Bcl-2 expression after temporary focal cerebral ischemia. Stroke, 31(9), 2212-7. [DOI:10.1161/01. STR.31.9.2212] [PMID]

Seifi, B., Kadkhodaee, M., Najafi, A., \& Mahmoudi, A (2014). Protection of liver as a remote organ after renal ischemia-reperfusion injury by renal ischemic postconditioning. International Journal of Nephrology, 2014, 120391 [DOI:10.1155/2014/120391] [PMID] [PMCID] 
Shabani, M., Larizadeh, M. H., Parsania, S., Asadi Shekaari, M., \& Shahrokhi, N. (2012). Profound destructive effects of adolescent exposure to vincristine accompanied with some sex differences in motor and memory performance. Canadian Journal of Physiology and Pharmacology, 90(4), 379-86. [DOI:10.1139/y11-132] [PMID]

Shabani, M., Nazeri, M., Parsania, S., Razavinasab, M., Zangiabadi, N., \& Esmaeilpour, K., et al. (2012). Walnut consumption protects rats against cisplatin-induced neurotoxicity. Neurotoxicology, 33(5), 1314-21. [DOI:10.1016/j.neuro.2012.08.004] [PMID]

Singh, M., \& Su, C. (2013). Progesterone, brain-derived neurotrophic factor and neuroprotection. Neuroscience, 239, 84-91. [DOI:10.1016/j.neuroscience.2012.09.056] [PMID] [PMCID]

Skelly, D. T., Hennessy, E., Dansereau, M. A., \& Cunningham, C. (2013). A systematic analysis of the peripheral and CNS effects of systemic LPS, IL-1 $\beta$, TNF- $\alpha$ and IL- 6 challenges in C57BL/6 mice. PloS one, 8(7), e69123. [DOI:10.1371/journal. pone.0069123] [PMID] [PMCID]

Sun, K., Liu, Z. S., \& Sun, Q. (2004). Role of mitochondria in cell apoptosis during hepatic ischemia-reperfusion injury and protective effect of ischemic postconditioning. World Journal of Gastroenterology, 10(13), 1934-8. [DOI:10.3748/wjg.v10. i13.1934] [PMID] [PMCID]

Tahamtan, M., Allahtavakoli, M., Abbasnejad, M., Roohbakhsh, A., Taghipour, Z., \&Taghavi, M., et al. (2013). Exercise preconditioning improves behavioral functions following transient cerebral ischemia induced by 4 -vessel occlusion (4-VO) in rats. Archives Of Iranian Medicine, 16(12), 697-704. [PMID]

Tsang, A., Hausenloy, D. J., Mocanu, M. M., \& Yellon, D. M. (2004). Postconditioning: A form of modified reperfusion protects the myocardium by activating the phosphatidylinositol 3-kinase-Akt pathway. Circulation Research, 95(3), 230-2. [DOI:10.1161/01.RES.0000138303.76488.fe] [PMID]

Tsao, N., Hsu, H. P., Wu, C. M., Liu, C. C., \& Lei, H. Y. (2001). Tumour necrosis factor-a causes an increase in blood-brain barrier permeability during sepsis. Journal of Medical Microbiology, 50(9), 812-21. [DOI:10.1099/0022-1317-50-9-812] [PMID]

Vetrovoi, O. V., Rybnikova, E. A., Glushchenko, T. S., \& Samoilov, M. O. (2015). Effects of hypoxic postconditioning on the expression of antiapoptotic protein Bcl-2 and neurotrophin BDNF in hippocampal field CA1 in rats subjected to severe hypoxia. Neuroscience and Behavioral Physiology, 45(4), 367-70. [DOI:10.1007/s11055-015-0083-y]

Vetrovoŭ, O., Rybnikova, T., \& Samorlov, M. (2013). [Effect of hypoxic postconditioning on the expression of antiapoptotic protein Bcl-2 and neurotrophin BDNF in CA1 hippocampal field of rats surviving severe hypoxia (Russian)]. Morfologiia, 145(2), 16-20. [PMID]

Wang, D., \& Corbett, D. (1990). Cerebral ischemia, locomotor activity and spatial mapping. Brain Research, 533(1), 78-82. [DOI:10.1016/0006-8993(90)91798-L] [PMID]

Wang, J. Y., Shen, J., Gao, Q., Ye, Z. g., Yang, S. Y., \& Liang, H. W., et al. (2008). Ischemic postconditioning protects against global cerebral ischemia/reperfusion-induced injury in rats. Stroke, 39(3), 983-90. [DOI:10.1161/STROKEAHA.107.499079] [PMID]

Wever, K. E., Menting, T., Masereeuw, R., van der Vliet, J. A., Rongen, G. A., \& Warlé, M. C. (2012). Local and remote ischemic postconditionings have synergistic protective effects on renal ischemia-reperfusion injury. Transplantation, 94(1), e1-e2 [DOI:10.1097/TP.0b013e318257ad76] [PMID]

Wu, D., \& Pardridge, W. M. (1999). Neuroprotection with noninvasive neurotrophin delivery to the brain. Proceedings of the National Academy of Sciences, 96(1), 254-9. [DOI:10.1073/ pnas.96.1.254] [PMID] [PMCID]

Yan, X. B., Hou, H. L., Wu, L. M., Liu, J., \& Zhou, J. N. (2007). Lithium regulates hippocampal neurogenesis by ERK pathway and facilitates recovery of spatial learning and memory in rats after transient global cerebral ischemia. Neuropharmacology, 53(4), 487-95. [DOI:10.1016/j.neuropharm.2007.06.020] [PMID]

Zen'ko, M., Rybnikova, Y., \& Glushchenko, T. S. (2014). [Expression of BDNF neurotrophin in the hippocampus and neocortex of rats during the development of post-stress anxiety and its correction by hypoxic postconditioning (Russian)]. Morfologiia, 146(5), 14-18. [PMID]

Zhang, X., Zhang, Q., Tu, J., Zhu, Y., Yang, F., \& Liu, B., et al. (2015). Prosurvival NMDA 2A receptor signaling mediates postconditioning neuroprotection in the hippocampus. Hippocampus, 25(3), 286-96. [DOI:10.1002/hipo.22372] [PMID]

Zhao, H. (2009). Ischemic postconditioning as a novel avenue to protect against brain injury after stroke. Journal of Cerebral Blood Flow \& Metabolism, 29(5), 873-85. [DOI:10.1038/jcbfm.2009.13] [PMID] [PMCID]

Zhao, H., Sapolsky, R. M., \& Steinberg, G. K. (2006). Interrupting reperfusion as a stroke therapy: Ischemic postconditioning reduces infarct size after focal ischemia in rats. Journal of Cerebral Blood Flow \& Metabolism, 26(9), 1114-21. [DOI:10.1038/ sj.jcbfm.9600348] [PMID]

Zhao, Z. Q. (2010). Postconditioning in reperfusion injury: A status report. Cardiovascular Drugs and Therapy, 24(3), 265-79. [DOI:10.1007/s10557-010-6240-1] [PMID]

Zhao, Z. Q., Corvera, J. S., Halkos, M. E., Kerendi, F., Wang, N. P., \& Guyton, R. A., et al. (2003). Inhibition of myocardial injury by ischemic postconditioning during reperfusion: Comparison with ischemic preconditioning. American Journal of Physiology-Heart and Circulatory Physiology, 285(2), H579-H588. [DOI:10.1152/ajpheart.01064.2002] [PMID] 